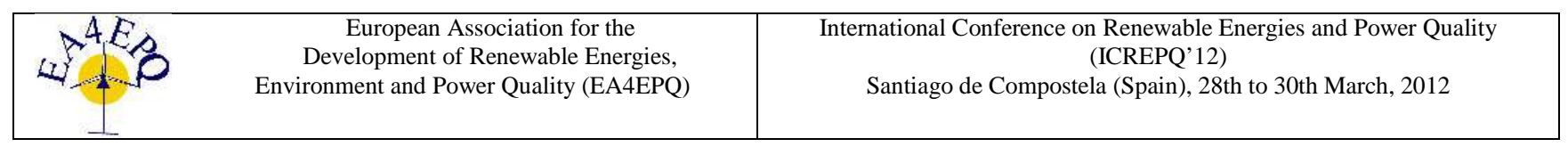

\title{
Converter with Wide Input Voltage Range Applied to Solid State Lighting Based on HV9930
}

\author{
R. A. Lodo, E. A. A. Coelho, F. V. R. Da Silva, A. W. F. V. Silveira, L. C. G. Freitas, J. B. Vieira Jr. \\ Universidade Federal de Uberlândia (UFU) \\ Faculdade de Engenharia Elétrica (FEELT) \\ Núcleo de Pesquisa em Eletrônica de Potência (NUPEP) \\ Uberlândia-MG, Brasil 38400-902 \\ e-mail: rafaellodo@hotmail.com, batista@ufu.br
}

\begin{abstract}
Currently research has pointed to LEDs as the technology more efficient and durable to be used in lighting, however, it requires a static converter in order to control the electrical current flowing through the LED lamp. In this context, this paper describes the implementation of a DC/DC converter with wide input voltage range called Boost-Buck Quadratic, with simple control strategy, driving a LED lamp. The converter can be powered from $12 \mathrm{~V}_{\mathrm{DC}}$ (battery voltage) to the universal $\mathrm{AC}$ input voltage (90 to $240 \mathrm{~V}_{\mathrm{AC}}$ ). Theoretical analysis, design guidelines and experimental results from a prototype of the proposed Boost-Buck Quadratic converter driving a $12 \mathrm{~W}$ LED lamp are shown in this paper.
\end{abstract}

\section{Key words}

Wide input voltage range, DC/DC converter, LED lamp.

\section{Introduction}

Nowadays, there is a great concern about the technologies used in lighting, among them one can outline: efficiency, durability, robustness, free from heavy metals in manufacturing, and others. On the contrary to other lamps, LEDs (Light Emitting Diodes) provide all these characteristics and are the most viable alternative existing on the market. The following topics describe some advantages of LEDs [1]:

-Extremely long lifetime, approximately 50,000 hours.

-Extremely robust, because there are no filaments or glass components, then it becomes insensitive to movements and vibrations.

-It does not emit UV or IR.

-It can be dimmed smoothly from full load to noload.
Apart from the advantages described previously, in [3] it is presented a comparative study of public system lighting between high-pressure sodium vapor lamps and solid-state lighting (LEDs), demonstrating the advantages of LED in relation to average illuminance, CRI (Color Rendering Index), energy consumption, long lifetime, and it shows that the human eye is more sensitized to some light wavelengths, depending on the photometric condition. Then, a light source with a lower luminous efficiency $(\mathrm{lm} / \mathrm{W})$, which is the case of LEDs, can be more sensitizing to the human eye compared to a light source with a great luminous efficiency, which is the case of the high-pressure sodium vapor lamps, when they focus on the same surface.

Thus, knowing that LEDs are more efficient and the global energy consumption with lighting is estimated in about $19 \%$ of the total amount of energy consumed in the world [2], it is possible to estimate that this percentage can be reduced by its half using the solid-state lighting, representing about $10 \%$ of the total energy consumption [3].

Although LEDs lighting provides a significant reduction of energy consumption, its implementation cost still being high, and there are high-pressure sodium vapor lamps which have higher luminous efficiency than LEDs. However, according to [4], there is a theory for lighting LEDs that mentions that LED brightness increases in thirty times every ten years and it costs decreases ten times in the same period. Then, it is expected that in next years, there will be more efficient LEDs offered for a more accessible price.

Concerning the development of LED drivers, previous works had presented proposals of cascade converters providing a wide input voltage range [5]-[8]. However, depending on the application, converters are designed to increase or decrease the input voltage, according to the rated voltage of the LED lamp to be driven. Therefore, 
LED drivers with a wide input voltage range are very attractive, because it could operate the same LED lamp for emergency (powered at $12 \mathrm{~V}_{\mathrm{DC}}$ ) or conventional lighting $\left(90-240 \mathrm{~V}_{\mathrm{AC}}\right)$.

Based in this context, this paper presents the implementation and the experimental analysis of a BoostBuck Quadratic converter, also known Boost-Buck2, designed to drive power LEDs using a single active switch. The converter can operate with an input voltage varying from $12 \mathrm{~V}_{\mathrm{DC}}$ (battery voltage) to the universal $\mathrm{AC}$ input voltage $\left(90-240 \mathrm{~V}_{\mathrm{AC}}\right)$. Despite of this wide input voltage range, the control technique and its implementation is quite simple. In order to verify the effectiveness of the proposed converter driving a LED lamp, detailed theoretical and experimental analyses are presented in this paper.

\section{Boost-Buck2 Converter}

The Boost-Buck2 converter is equivalent to the conventional Boost cascaded with two Buck converters and, consequently, it can operate as step-up or as stepdown converter. When it operates as step-up its gain depends directly on the duty cycle and while it operates as step-down its gain has a quadratic relationship with the duty cycle. Moreover, the converter has current source characteristic as much input as output, and with the advantages of using an active single switch. The schematic of the converter is showed in Fig. 1.

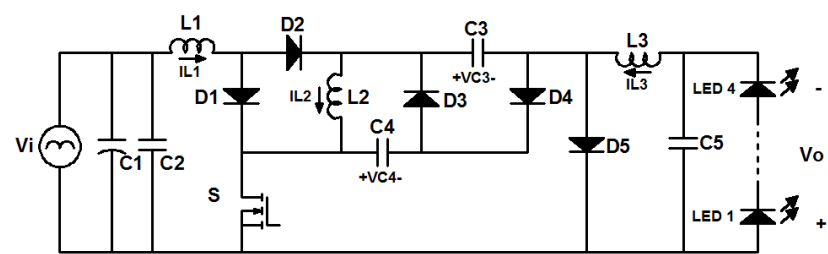

Fig. 1. Schematic of converter Boost-Buck2.

Converter operating at steady state, with the current through the inductors in continuous conduction mode (CCM), presents two operation stages.

First stage: This stage starts when switch $\mathrm{S}$ is turned-on. During this stage diodes $\mathrm{D}_{1}$ and $\mathrm{D}_{4}$ are forward-biased, and diodes $D_{2}, D_{3}$ and $D_{5}$ are reverse-biased, inductor $L_{1}$ is charged linearly by source $\mathrm{V}_{\mathrm{i}}$ and inductors $\mathrm{L}_{2}$ and $\mathrm{L}_{3}$ are charged linearly by capacitors $C_{3}, C_{4}$ and $C_{5}$. Fig. 2 illustrates the first stage of operation.

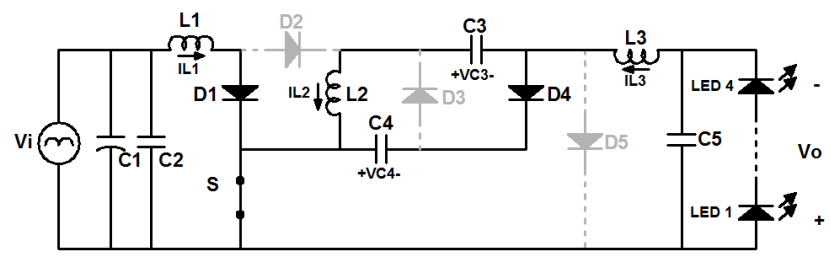

Fig. 2. First stage of operation of Boost-Buck2 converter.

Second stage: This stage starts when switch $\mathrm{S}$ is turned-off and finishes when switch $\mathrm{S}$ is turned-on. During this stage diodes $\mathrm{D}_{2}, \mathrm{D}_{3}$ and $\mathrm{D}_{5}$ are forward-biased and diodes $\mathrm{D}_{1}$ and $\mathrm{D}_{4}$ are reverse-biased. Current through the inductors decrease linearly, and in that way, inductor $\mathrm{L}_{1}$ supplies capacitor $\mathrm{C}_{3}$, inductor $\mathrm{L}_{2}$ supplies capacitor $\mathrm{C}_{4}$ and inductor $\mathrm{L}_{3}$ and capacitor $\mathrm{C}_{5}$ supplies LED lamp. Fig. 3 illustrates the second stage of operation.

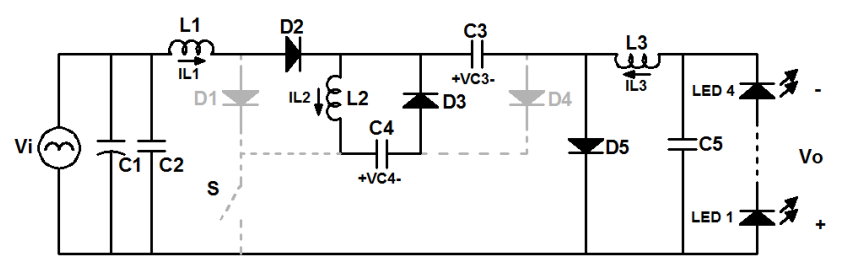

Fig. 3. Second stage of operation of Boost-Buck2 converter.

Fig. 4, 5, 6 and 7 show the main theoretical waveforms of Boost-Buck 2 converter.

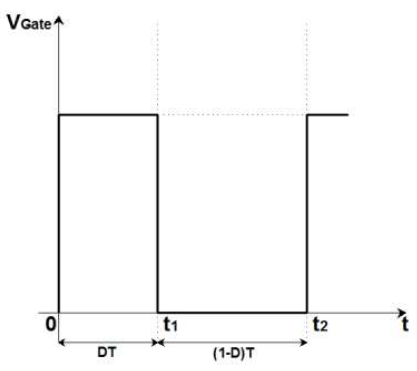

Fig. 4. Voltage waveform on gate of switch S.

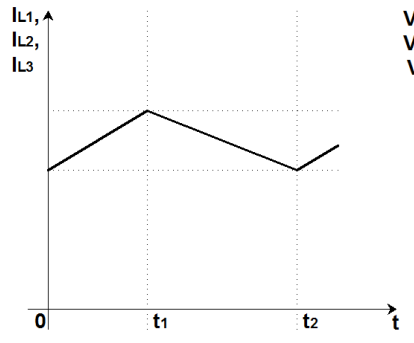

a)

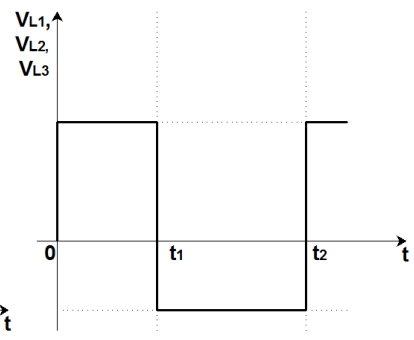

b)
Fig. 5. (a) Current and (b) voltage waveforms of inductors $L_{1}$, $\mathrm{L}_{2}$ and $\mathrm{L}_{3}$.

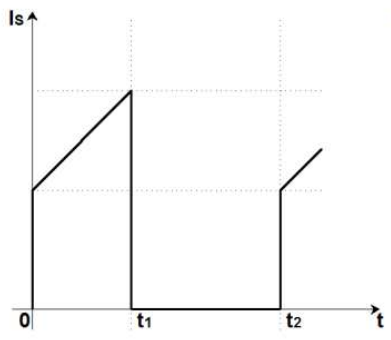

a)

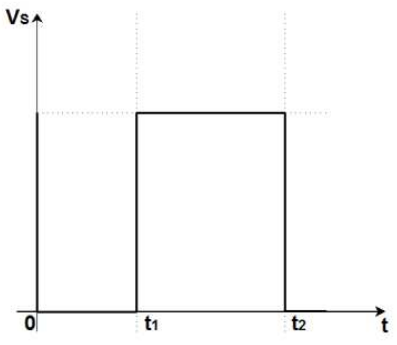

b)
Fig. 6. (a) Current and (b) voltage waveforms of switch S.

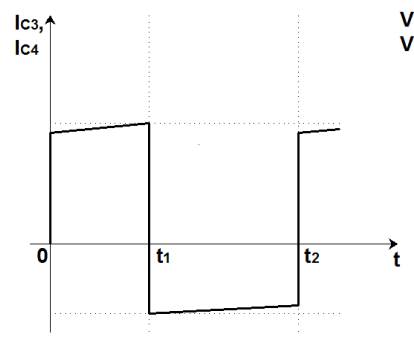

a)

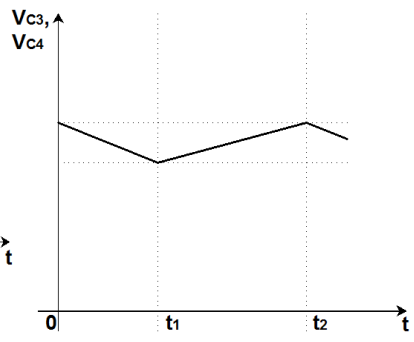

b)
Fig. 7. (a) Current and (b) voltage waveforms of capacitors C3 and $\mathrm{C}$. 


\section{Basic Equations}

Knowing that integral of voltage across the inductors for one switching period is zero, yields:

For inductor $\mathrm{L}_{1}$.

$$
V_{i} D T-\left(V_{i}-V_{C_{3}}\right)(1-D) T=0
$$

Solving ( 1 ) for $\mathrm{V}_{\mathrm{C} 3}$, yields:

$$
V_{C_{3}}=\frac{V_{i}}{(1-D)}
$$

For inductor $\mathrm{L}_{2}$.

$$
\left(V_{C_{3}}-V_{C_{4}}\right) D T-V_{C_{4}}(1-D) T=0
$$

Solving ( 3 ) for $\mathrm{V}_{\mathrm{C} 4}$, yields:

$$
V_{C_{4}}=V_{C_{3}} \cdot D
$$

For inductor $\mathrm{L}_{3}$.

$$
\left(V_{C_{4}}-V_{O}\right) D T-V_{O}(1-D) T=0
$$

Solving ( 5 ) for $\mathrm{V}_{0}$, yields:

$$
V_{O}=V_{C_{5}}=V_{C_{4}} \cdot D
$$

Replacing ( 2 ) and ( 4 ) in ( 6 ), yields:

$$
V_{O}=V_{C_{5}}=\frac{D^{2}}{(1-D)} \cdot V_{i}
$$

From ( 7 ) it is found the equation of static gain of BoostBuck2 converter.

$$
G=\frac{V_{0}}{V_{i}}=\frac{D^{2}}{(1-D)}
$$

Knowing that the integral of current through the inductors for one switching period is zero, yields:

For capacitor $\mathrm{C}_{3}$.

$$
I_{L_{2}} D T-I_{L_{1}}(1-D) T=0
$$

Solving ( 9 ) for $\mathrm{I}_{\mathrm{L} 2}$, yields:

$$
I_{L_{1}}=I_{L_{2}} \frac{D}{(1-D)}
$$

For capacitor $\mathrm{C}_{4}$.

$$
\left(I_{L_{3}}-I_{L_{2}}\right) D T-I_{L_{2}}(1-D) T=0
$$

Solving ( 11 ) for $\mathrm{I}_{\mathrm{L} 2}$, yields:

$$
I_{L_{2}}=I_{L_{3}} \cdot D
$$

For capacitor $\mathrm{C}_{5}$.

$$
\left(I_{0}-I_{L_{3}}\right) D T-\left(I_{L_{3}}-I_{0}\right)(1-D) T=0
$$

Solving ( 13 ) for $\mathrm{I}_{0}$, yields:

$$
I_{L_{3}}=I_{O}
$$

From ( 12 ) and ( 14 ), yields:

$$
I_{L_{2}}=I_{O} \cdot D
$$

From ( 10 ), ( 12 ) and ( 14 ), yields:

$$
I_{L_{1}}=\frac{D^{2}}{(1-D)} I_{O}
$$

Fig. 8 shows the static gain of converter.

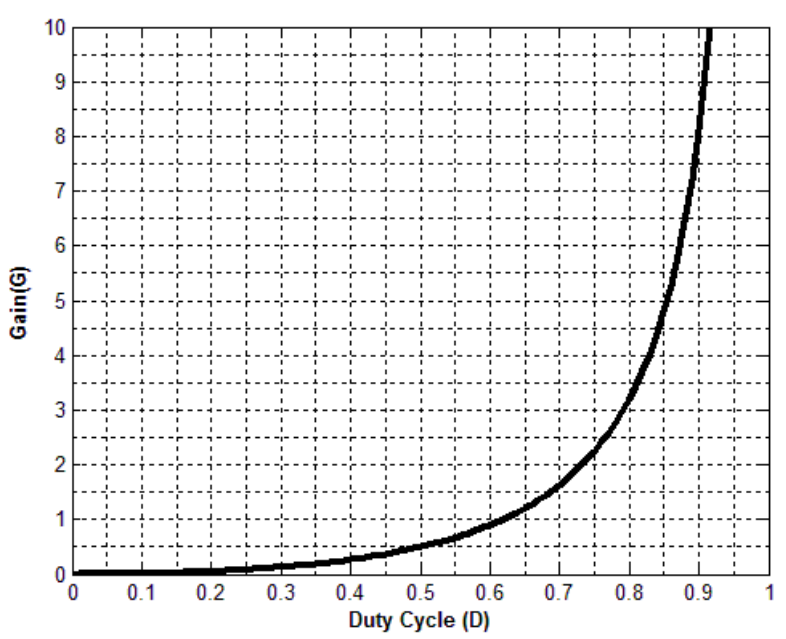

Fig. 8. Static gain of Boost-Buck converter

\section{Control with HV9930}

HV9930 is a control integrated circuit for variable frequency PWM, manufactured by Supertex ${ }^{\circledR}$, applicable to converters with the Boost-Buck topology driving LEDs. Its great advantage is its quite simple implementation, because it has an internal linear regulator, allowing it to be powered directly from 8.0 to $200 \mathrm{~V}_{\mathrm{DC}}$, maintaining the voltage VDD at $7.5 \mathrm{~V}$ (see Fig. 9). Moreover, the GATE pin can be connected directly to the MOSFET, and there's no need of isolation circuit and pulse amplification. However, it is recommended that the MOSFET input capacitance (Ciss) not exceed $1000 \mathrm{pF}$.

The load current control is realized by two identical comparators, of which its inverting input is connected to a built-in $100 \mathrm{mV}$. In this manner, when the gate is high, the inverting input is connected to GND, and when the gate is 
low it is connected to $100 \mathrm{mV}$. The input comparator acts in the control during an overload or in the start-up condition, limiting the converter input current. The output comparator controls the converter output current, which it's maintained between a lower and an upper limit (hysteresis) [9], [10].

Fig. 9 shows block diagram of IC HV9930.

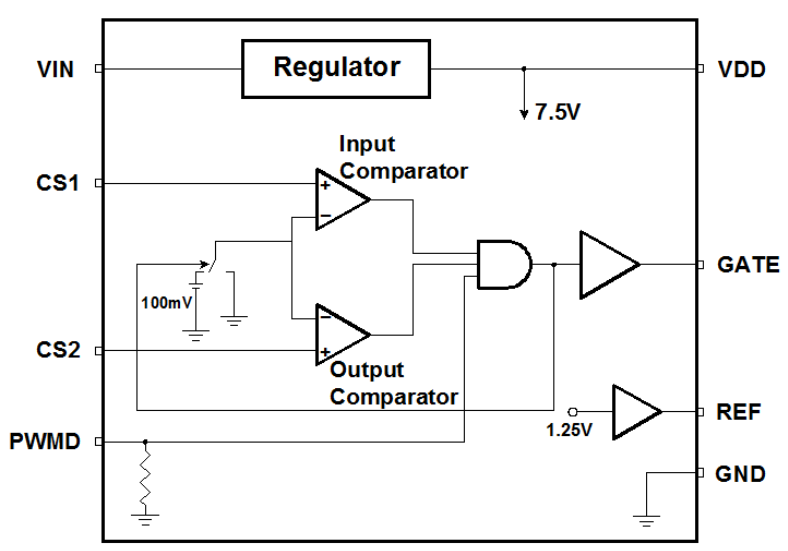

Fig. 9. Block Diagram of IC HV9930

Fig. 10 shows the schematic of Boost-Buck2 converter based on the HV9930. It's possible to observe that components $\mathrm{R}, \mathrm{T}$ and $\mathrm{Z}_{1}$, make up the start-up circuit. Components $\mathrm{L}_{1 \mathrm{f}}, \mathrm{L}_{2 \mathrm{f}}, \mathrm{D}_{\mathrm{f}}$ and $\mathrm{C}_{\mathrm{f}}$, make up an auxiliary power supply that powers the IC in steady state and, this way, continuing the steady state mode, diode $\mathrm{D}_{6}$ is reverse-biased minimizing the energy dissipation in transistor $\mathrm{T}$. Resistors $\mathrm{R}_{\mathrm{cs} 1}, \mathrm{R}_{\mathrm{s} 1}$ and $\mathrm{R}_{\mathrm{ref} 1}$, makes up input current sensor and $\mathrm{R}_{\mathrm{cs} 2}, \mathrm{R}_{\mathrm{sa}}, \mathrm{R}_{\mathrm{sb}}$ and $\mathrm{R}_{\mathrm{ref} 2}$, make up output current sensor.

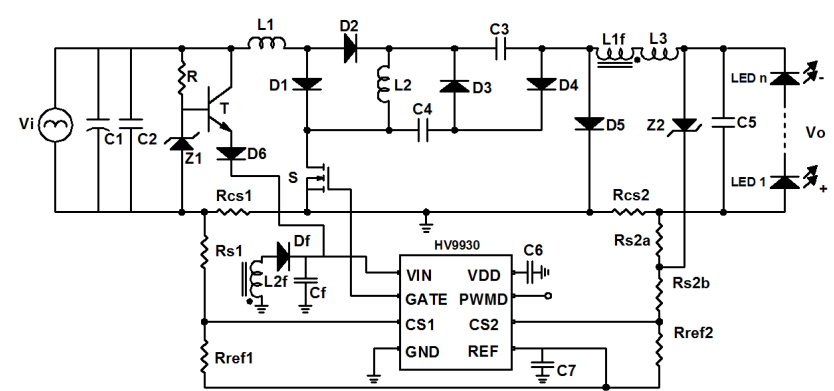

Fig. 10. Schematic of Boost-Buck2 converter based on the HV9930

\section{Design of Boost-Buck2 Converter}

The design parameters of the Boost-Buck2 converter are shown in Table I

For the inductors design $\mathrm{L}_{1}, \mathrm{~L}_{2}$ and $\mathrm{L}_{3}$ of Boost-Buck2 converter, it will be considered maximum input voltage, $\mathrm{V}_{\text {imáx }}=340 \mathrm{~V}_{\mathrm{DC}}$, which is the critical case for inductors, and from ( 8 ) it is found that $\mathrm{D}_{\min }=0.2$.

From first stage of operation, yields:

$$
V_{i}=V_{L_{1}}=L_{1} \frac{d i_{L_{1}}}{d t_{1}}
$$

Table I. - Design parameters of the Boost-Buck2 converter

\begin{tabular}{cc}
\hline PARAMETERS & VALUE \\
\hline Output power & $\mathrm{P}_{0}=12 \mathrm{~W}$ \\
\hline Output current & $\mathrm{I}_{0}=700 \mathrm{~mA}$ \\
\hline Output voltage & $\mathrm{V}_{0}=16 \mathrm{~V}$ \\
\hline Minimum input voltage & $\mathrm{V}_{\mathrm{imin}}=12 \mathrm{~V}_{\mathrm{DC}}$ \\
\hline Maximum input voltage & $\mathrm{V}_{\mathrm{imax}}=340 \mathrm{~V}_{\mathrm{DC}}$ \\
\hline Current ripple in $\mathrm{L}_{1}$ & $\Delta \mathrm{I}_{\mathrm{L} 1}=0.9 \cdot \mathrm{I}_{\mathrm{L} 1}$ \\
\hline Current ripple in $\mathrm{L}_{2}$ & $\Delta \mathrm{I}_{\mathrm{L} 2}=0.9 \cdot \mathrm{I}_{\mathrm{L} 2}$ \\
\hline Current ripple in $\mathrm{L}_{3}$ & $\Delta \mathrm{I}_{\mathrm{L} 3}=0.2 \cdot \mathrm{I}_{\mathrm{L} 3}$ \\
\hline Voltage ripple in $\mathrm{C}_{3}$ & $\Delta \mathrm{V}_{\mathrm{C} 3}=0.2 \cdot \mathrm{V}_{\mathrm{C} 3}$ \\
\hline Voltage ripple in $\mathrm{C}_{4}$ & $\Delta \mathrm{V}_{\mathrm{C} 4}=0.2 \cdot \mathrm{V}_{\mathrm{C} 4}$ \\
\hline Voltage ripple in $\mathrm{C}_{5}$ & $\Delta \mathrm{V}_{\mathrm{C} 5}=2 \mathrm{~V}$ \\
\hline Minimum switching frequency & $\mathrm{f}_{\mathrm{smin}}=80 \mathrm{kHz}$ \\
\hline Predicted efficiency & $\eta=0.8$ \\
\hline
\end{tabular}

Solving ( 17 ) for $\mathrm{L}_{1}$ and from ( 16 ), yields:

$$
L_{1}=\frac{V_{i}}{\Delta_{L_{1}}} D_{\text {min }} \cdot T_{s_{\text {min }}} \Rightarrow L_{1} \cong 27 \mathrm{mH}
$$

From the second stage of operation, yields:

$$
V_{C_{4}}=-V_{L_{2}}=-L_{2} \frac{d i_{L_{2}}}{d t_{2}}
$$

Solving ( 19 ) for $\mathrm{L}_{2}$, and from ( 6 ), yields:

$$
L_{2}=\frac{V_{0}\left(1-D_{\min }\right)}{D \cdot \Delta I_{L_{2}}} T_{s_{\min }} \Rightarrow L_{2} \cong 6.7 \mathrm{mH}
$$

From the second stage of operation, yields:

$$
V_{O}=-V_{L_{3}} \Rightarrow V_{O}=-L_{3} \frac{d i_{L_{3}}}{d t_{2}}
$$

The negative sign in ( 21 ), indicates that the output voltage polarity is reversed with respect to the input voltage.

Solving ( 21 ) for $\mathrm{L}_{3}$, and from ( 14 ), yields:

$$
L_{3}=\frac{V_{O}\left(1-D_{\text {min }}\right)}{\Delta I_{L_{3}}} T_{s_{\text {min }}} \Rightarrow L_{3} \cong 1.1 \mathrm{mH}
$$

For the capacitors design $\mathrm{C}_{3}, \mathrm{C}_{4}$ e $\mathrm{C}_{5}$ of Boost-Buck2 converter, it will be considered the minimum input voltage, $\mathrm{V}_{\mathrm{imin}}=12 \mathrm{~V}_{\mathrm{DC}}$, which is the critical case to the capacitors, and from ( 8 ) it is found that $D_{\text {máx }}=0,67$.

Filter capacitor of the rectifier can be calculated by [11]:

$$
C_{1}=\frac{P_{i}}{f_{r e t}\left(V_{i p k}^{2}-\left(0,9 \cdot V_{i p k}\right)^{2}\right)} \Rightarrow C_{1} \cong 41 \mu F
$$

Capacitor C2 was placed in parallel with capacitor C1 and it has a purpose of improving the response at high 
frequencies. C2 was empirically defined, and was chosen polyester capacitor $560 \eta \mathrm{F}$.

From the first stage of operation, yields:

$$
I_{L_{2}}=-I_{C_{3}}=-C_{3} \frac{d V_{C_{3}}}{d t_{1}}
$$

Solving ( 24 ) for $\mathrm{C}_{3}$, and from ( 2 ) and ( 15 ), yields:

$$
C_{3}=\frac{I_{L_{2}} D_{\max }}{\Delta V_{C_{3}}} \cdot T_{S_{\min }} \Rightarrow C_{3} \cong 540 \eta F
$$

From the second stage of operation, yields:

$$
I_{L_{2}}=I_{C_{4}}=C_{4} \frac{d V_{C_{4}}}{d t_{2}}
$$

Solving ( 26 ) for $\mathrm{C}_{4}$, and from ( 6 ) and ( 15 ), yields:

$$
C_{4}=\frac{I_{L_{2}}\left(1-D_{\text {max }}\right)}{\Delta V_{C_{4}}} \cdot T_{S_{\text {min }}} \Rightarrow C_{4} \cong 405 \eta F
$$

If disregarded current ripple in the load, then $\Delta \mathrm{I}_{\mathrm{L} 3}=\Delta \mathrm{I}_{\mathrm{C} 5}$. Thus, capacitor average current charge in time $T / 2$ is $\mathrm{I}_{\mathrm{C} 5}=\Delta \mathrm{I}_{\mathrm{L} 3} / 4$, then the voltage ripple on capacitor $\mathrm{C}_{5}$ [12], is:

$$
\Delta V_{C_{5}}=\frac{1}{C_{5}} \int_{0}^{\frac{T}{2}} \frac{\Delta I_{C_{5}}}{4} t d t=\frac{\Delta I_{C_{5}}}{8 C_{5} f}
$$

Hence as $\Delta \mathrm{I}_{\mathrm{L} 3}=\Delta \mathrm{I}_{\mathrm{C} 5}$, and from ( 22 ) and ( 28 ) it is obtained:

$$
C_{5}=\frac{V_{o}\left(1-D_{\max }\right)}{8 L_{3} f^{2} \Delta V_{C_{5}}} \cong 47 \eta F
$$

\section{Experimental Results}

The experimental results were achieved with a converter prototype, which was consisted of components described in Table II.

Table II. - Components Used In Prototype

\begin{tabular}{cc}
\hline COMPONENTS & VALUES \\
\hline Inductor $\mathrm{L}_{1}$ & $27 \mathrm{mH}$ \\
\hline Inductor $\mathrm{L}_{2}$ & $6.7 \mathrm{mH}$ \\
\hline Inductor $\mathrm{L}_{3}$ & $1.1 \mathrm{mH}$ \\
\hline Electrolytic capacitor $\mathrm{C}_{1}$ & $47 \mu \mathrm{F}$ \\
\hline Polyester capacitor $\mathrm{C}_{2} \mathrm{e} \mathrm{C}_{3}$ & $560 \eta \mathrm{F}$ \\
\hline Polyester capacitor C & $390 \eta \mathrm{F}$ \\
\hline Polyester capacitor $\mathrm{C}_{5}$ & $47 \eta \mathrm{F}$ \\
\hline Mosfet S $_{4}$ & STD8NM60N-1 \\
\hline Diodes $\mathrm{D}_{1}, \mathrm{D}_{2}, \mathrm{D}_{3}, \mathrm{D}_{4} \mathrm{e}_{5}$ & HFA30TA60C \\
\hline LED $_{1}, \mathrm{LED}_{2}, \mathrm{LED}_{3}, \mathrm{e} \mathrm{LED}_{4}$ & EDSW-KLC8-B3/700 mA
\end{tabular}

Fig. 11 shows the prototype with LED lamp, and Fig. 12 shows current waveform in LED to the $V_{i}=12 V_{D C}$.

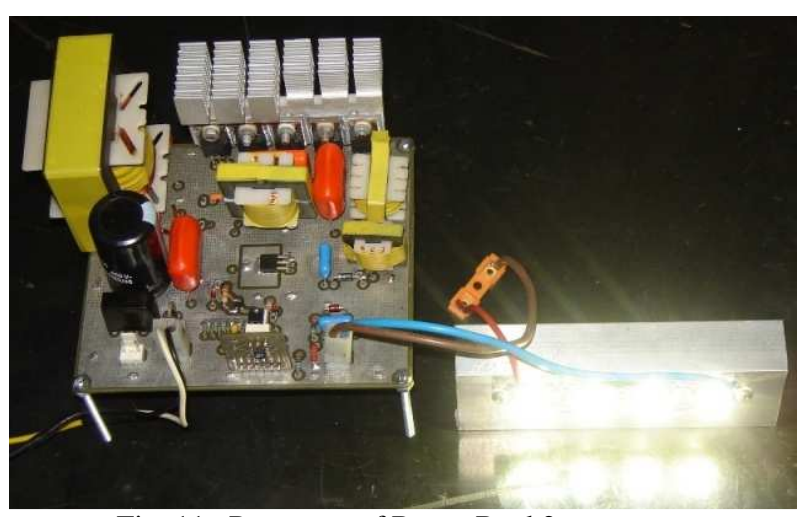

Fig. 11. Prototype of Boost-Buck2 converter

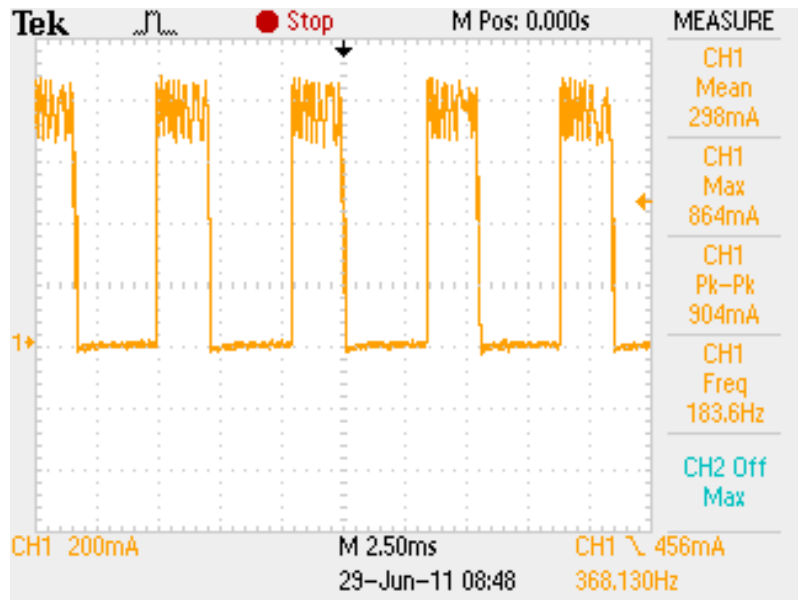

Fig. 12. Waveform to $\mathrm{Vi}=12 \mathrm{~V}_{\mathrm{DC}}$. (current in LED lamp $200 \mathrm{~mA} / \mathrm{Div})$.

As it can be noticed in Fig. 12, for minimum input voltage, $\mathrm{Vi}=12 \mathrm{VDC}$, the current through LED lamp is pulsed. This is an intrinsic characteristic of the control strategy of IC HV9930 applied to converters with wide input voltage range.

Knowing that the minimum voltage supply is only for operation in emergency lighting, it was looked into Standard NBR 10898:1999 [14]. Then, it was verified in laboratory that the illuminance which the LED lamp produces with the converter powered in $\mathrm{Vi}=12 \mathrm{VDC}$, meets the requirements of the standard previously mentioned. Even the current being pulsed, it's observed only the decrease on the brightness of the LEDs, but there's no occurrence of flicker.

Fig. 13 shows the current waveform in the LED lamp and the voltage waveform on switch $\mathrm{S}$, to input voltage from $\mathrm{Vi}=127$ VRMS. Thus, it was verified, for highest input voltage, the LED lamp current wasn't pulsed. Fig. 14 and Fig. 15 show the current waveforms in the LED lamp and voltage waveforms on switch $\mathrm{S}$, to input voltage from $\mathrm{Vi}=220 \mathrm{Vrms}$ and $\mathrm{Vi}=240 \mathrm{Vrms}$, respectively.

\section{Conclusion}

This paper had purpose of analyzing and designing the Boost-Buck2 converter and to evaluate its functionality using IC HV9930 for control of switch S. Thus, this topology brings great operational flexibility, because the converter was designed to operate from the battery voltage 


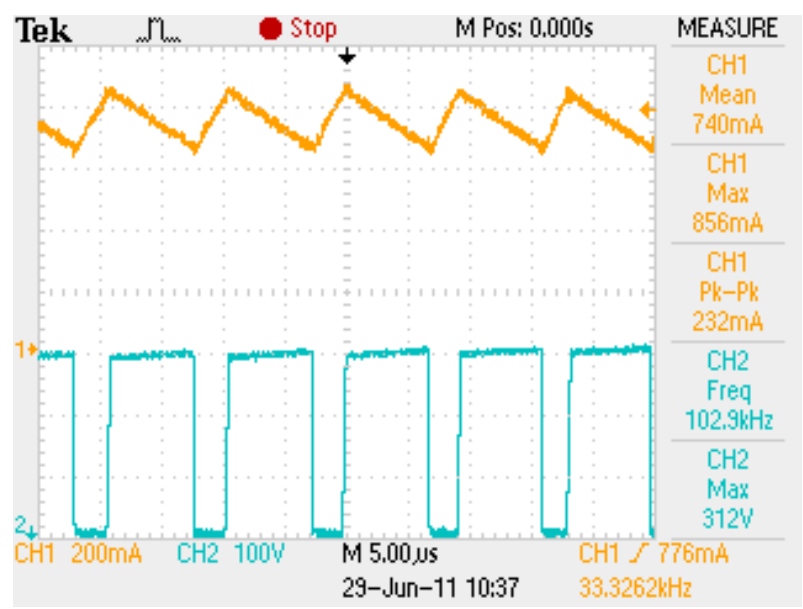

Fig. 13. Waveforms to $\mathrm{Vi}=127 \mathrm{~V}_{\text {RMS }}$. $(\mathrm{CH} 1-$ current in LED lamp - 200mA/Div, CH2 - voltage on switch $\mathrm{S}-100 \mathrm{~V} / \mathrm{Div})$.

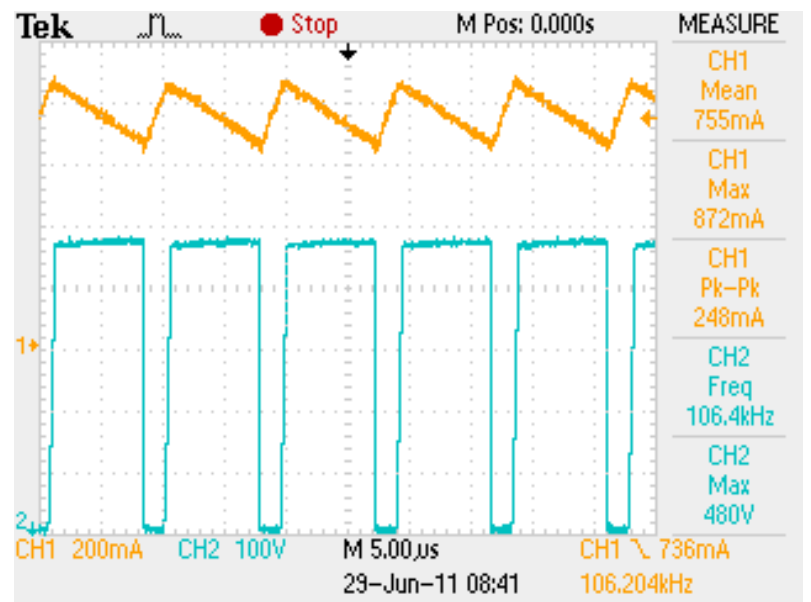

Fig. 14. Waveforms to $\mathrm{Vi}=220 \mathrm{~V}_{\mathrm{RMS}}$. $(\mathrm{CH} 1-$ current in LED lamp - 200mA/Div, CH2 - voltage on switch S - 100V/Div).

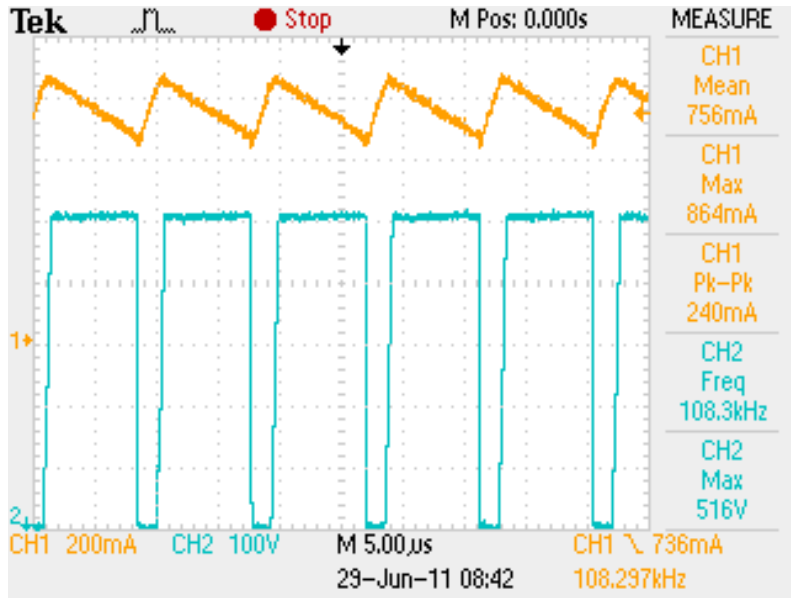

Fig. 15. Waveforms to $\mathrm{Vi}=240 \mathrm{~V}_{\mathrm{RMS}}$. $(\mathrm{CH} 1-$ current in LED lamp - 200mA/Div, CH2 - voltage on switch $\mathrm{S}-100 \mathrm{~V} / \mathrm{Div})$.

$\left(12 \mathrm{~V}_{\mathrm{DC}}\right.$ ) to the universal $\mathrm{AC}$ input voltage (90 to 240 $\mathrm{V}_{\mathrm{RMS}}$ ), moreover, the control technique and its implementation is quite simple with the IC HV9930.

Therefore, a single device can be used for emergency and conventional lighting. Thus, the converter turns it very attractive from the technical and economical standpoint for industrial and commercial applications.

Through computer simulations results and subsequent experimental verification on a prototype (shown in Fig. 11 ), it was verified that for minimum input voltage the current in the LED lamp was pulsed. Nevertheless, the results meet the standard NBR 10898:99. In the other hand, current in LED lamp to be pulsed, allows its junction to work at a lower temperature, increasing its lifetime.

For the universal AC input voltage (90 to $240 \mathrm{~V}_{\mathrm{RMS}}$ ), as shown in experimental results, the current in the LED lamp wasn't pulsed, proving the functionality of BoostBuck2 converter and of CI HV9930.

\section{Acknowledgment}

The authors gratefully acknowledge the financial support of Conselho Nacional de Desenvolvimento Científico e Tecnológico - CNPQ - Brazil.

\section{References}

[1] de Britto, J.R.; de Freitas, L.C.; Farias, V.J.; Coelho, E. Vieira, J.B., "LED Lamp Driver Using a Converter with Wide Range Conversion Microcontroller-Based", Industrial Electronics, 2008. IECON 2008. 34th Annual Conference of IEEE, pp: 1988 - 1993, 10-13 Nov. 2008.

[2] http://www.metodoeventos.com.br/6eficienciaenergetica/palest ras/22_07_workshop2/eduardo_polidoro.pdf, "Iluminação Eficiente com LEDs", Eduardo Polidoro, Philips, acessed 04/29/2011.

[3] Rodrigues, C.R.B.S.; Almeida, P.S.; Soares, G.M.; Jorge, J.M. Pinto, D.P.; Braga, H.A.C, "Um Estudo Comparativo de Sistemas de Iluminação Pública: Estado Sólido e Lâmpadas de Vapor de Sódio em Alta Pressão", Industry Applications (INDUSCON), 2010 9th IEEE/IAS International Conference on, pp: 1-6, 8-10 Nov. 2010.

[4] Liu YU, Jinming YANG, "The Topologies of White LED Lamp's Power Drivers", Power Electronics Systems and Applications, 2009. PESA 2009. 3rd International Conference on, pp: 1-6, 20-22 May 2009.

[5] Demian, A.E., Reginaldo de Britto, J., de Freitas, L.C., Farias, V.J., Coelho, E.A.A., Vieira, J.B., “ Microcontroller-Based Quadratic Buck Converter Used as LED Lamp Driver", Power Electronics And Aplication , 2007 European Conference on, pp: 1-6, Sept. 2007

[6] Bassan, S., Moschopoulos, G., "Properties and Applications of Quadratic Converters", IEEE Canada Electrical Power Conference, pp: 123-127, Oct. 2007.

[7] Alonso, J.M., Viña, J., Gacio, D., Campa, L., Martínez, G., Osorio, R., "Analysis and Design of the Quadratic Buck-Boost Converter as a High-Power-Factor Driver for Power-LED Lamps", IECON $2010-36^{\text {th }}$ Annual Conference on IEEE Industrial Electronics Society, pp: 2541-2546, Nov. 2010.

[8] Silva, W.G., Rodovalho, D.S., da Silva, F.V.R., de Morais, J.S., de Freitas, L.C., Coelho, E.A.A., Vieira Junior, J.B., “ Conversor Boost Quadrático-Buck Utilizado no Acionamento de um Vetor de LED Empregado no Tratamento de Disfunções Celulares", Eletrônica de Potência, vol. 16, $\mathrm{N}^{\circ}$ 3, Jun./Aug. 2011

[9] Supertex inc., "Hysteretic Boost-Buck (Cuk) Led Driver IC HV9930", 2008 Supertex inc.

[10] Steve Winder, "Power Supplies for LED Drives", Newnes, 2008.

[11] Barbi, I., "Projetos de Fontes Chaveadas", Edition of the author, Florianópolis, 2001.

[12] Rashid, Muhammad H., "Eletrônica de Potência: Circuitos, Dispositivos e Aplicações”, Makronn Books, São Paulo, 1999.

[13] http://www.edison-opto.com.tw/Datasheet/Edixeon/Edison\%20 Opto_Edixeon\%C2\%AE\%20K\%20Series_Eng_v4.pdf, accessed 06/28/2011.

[14] NBR 10898:1999 -“Emergency Lighting System” 